\title{
An andesitic source for Jack Hills zircon argues for a Hadean onset of plate tectonics
}

\author{
SIMON TURNER', SIMON WILDE', GERHARD WÖRNER',
} BRUCE SCHAEFER', YI-JEN LAI'

Department of Earth and Environmental Sciences, Macquarie University, NSW 2109, Australia

Bruce.Schaefer@mq.edu.au

Department of Applied Geology, Curtin University, PO Box U1987, Perth 6845, Australia

${ }^{3}$ Abteilung Geochemie, Geowissenschaftliches Zentrum

Göttingen (GZG), Germany

The composition and origin of Earth's early crust remains hotly debated. Here we use partition coefficients to invert the trace element composition of 4.3-3.3 Gyr Jack Hills zircons to calculate the composition of the melts from which they crystallised. These were conducted using a new aliquot of zircons and ages were obtained using standard SHRIMP methodology, with trace elements determined by standard LA-ICP-MS techniques.

We applied the ratios of partition coefficients derived from the only experimental study which is consistent with the lattice strain model in order to mitigate against the temperature effects on trace element partitioning. Using this approach, the average $\mathrm{SiO}_{2}$ content of these melts was $59 \pm 6$ wt. \% with $\mathrm{Th} / \mathrm{Nb}, \mathrm{Dy} / \mathrm{Yb}$ and $\mathrm{Sr} / \mathrm{Y}$ ratios of $2.7 \pm 1.9,0.9 \pm$ 0.2 and $1.6 \pm 0.7$, respectively.

Such features strongly indicate that the protolith for the Jack Hills zircons was not an intra-plate mafic rock, nor a TTG (tondjhemite-tonalite-granodiorite) or a Sudbury-like impact melt. Instead, the inferred equilibrium melts are much more similar to andesites formed in modern subduction settings. Although subduction signatures need to not prove the operation of plate tectonics, our findings are entirely permissible of this. Further, we find no evidence for any secular variation between 4.3 and $3.3 \mathrm{Gyr}$ implying little change in the composition or tectonic affinity of the Earth's early crust from the Hadean to Mesoarchaean.

1: Burnham and Berry, 2012, Geochimica Cosmochim. Acta, 95, 196-212. 